\title{
The rolB-Like Part of the Agrobacterium rhizogenes orf8 Gene Inhibits Sucrose Export in Tobacco
}

\author{
Marie Umber, ${ }^{1}$ Lars Voll, ${ }^{2}$ Andreas Weber, ${ }^{2}$ Pierre Michler, ${ }^{1}$ and Léon Otten ${ }^{1}$ \\ ${ }^{1}$ Institut de Biologie Moléculaire des Plantes, CNRS UPR2357, Rue du Général Zimmer 12, 67084 Strasbourg, France; \\ ${ }^{2}$ Botanisches Institut, Gyrhofstrasse 15, D-50931, Köln, Germany
}

Submitted 9 October 2001. Accepted 23 April 2002.

\begin{abstract}
Many Agrobacterium T-DNA genes belong to the highly diverse rolB family. The mode of action of most of these genes is still unknown. rolB-like sequences also are present at the $5^{\prime}$ ends of the T-DNA-located iaaM genes and the iaaM homolog orf8, whereas iaaM genes from Pseudomonas and Erwinia spp. lack such sequences. iaaM genes encode tryptophan monooxygenases; these enzymes convert tryptophan into indole-3-acetamide, a precursor of indole3-acetic acid. Tobacco plants expressing the rolB-like part of the A4 orf8 gene ( $2 \times 35 \mathrm{~S}-\mathrm{A} 4-\mathrm{Norf} 8$ plants) accumulate glucose, fructose, sucrose, and starch and resemble sucrose transporter (NtSUT1) antisense plants. Different lines of evidence indicate that $2 \times 35 S-A 4-N o r f 8$ plants export less sucrose from source leaves. Glucose, fructose, sucrose, and starch accumulate in source leaves during sink-source transition, whereas sink tissues like petioles and midveins contain lower levels than normal. Petiole exudation experiments demonstrate a significant decrease in export of label after ${ }^{14} \mathrm{C}$-sucrose infiltration and after ${ }^{14} \mathrm{CO}_{2}$ labeling. Grafting of stunted homozygous $2 \times 35 S-A 4-N o r f 8$ plants onto wild-type rootstocks restores growth, indicating that unloading is not affected. Growth of $2 \times 35 \mathrm{~S}-\mathrm{A4} 4-\mathrm{Norf8}$ seedlings is inhibited on naphthalene acetic acid-containing media, suggesting a link between sucrose transport and auxin sensitivity.
\end{abstract}

A large number of Agrobacterium T-DNA genes have been grouped into the highly diverged $\mathrm{rolB}$ family (Levesque et al. 1988; Otten and Schmidt 1998). This gene family can be divided into 16 subfamilies represented by genes rolB and $\mathrm{rolC}$ (Schmülling et al. 1988); 5 (Körber et al. 1991); 6a (Messens et al. 1985); $6 b$ (Hooykaas et al. 1988; Tinland et al. 1989, 1992; Wabiko and Minemura 1996); orf13 and orf14 (Hansen et al. 1993), $b, c^{\prime}, d, e, 3^{\prime}, 4^{\prime}$, and 7 (Otten et al. 1999); rolB rR $^{T R}$ (Lemcke and Schmülling 1998a); and lso (Otten and Schmidt 1998). The rolB-like genes encode proteins ranging in size from 180 to 260 amino acids; so far, no other homologs have been detected. Many induce morphological abnormalities in transgenic plants (Gaudin et al. 1994; Nilsson and Olsson 1997). Their modes of action are controversial or unknown but probably, in some way, related. RolB-like sequences have also been identified at the N-termini of all T-DNA-encoded IaaM (tryptophan 2-monooxygenase, six sequences) and Orf8 (related to IaaM, two sequences) proteins (Levesque et al. 1988). Pseudomonas savastanoi and Erwinia herbicola IaaM proteins (Comai and Kosuge 1982; Gafni et al. 1997) lack RolB-like sequences. Tryptophan 2-monooxygenases catalyze the forma-

Corresponding author: L Otten; E-mail: leon.otten@ ibmp-ulp.u-strasbg.fr tion of indole-3-acetamide (IAM) from tryptophan (Van Onckelen et al. 1985, 1986). Indole-3-acetamide hydrolases (encoded by $i a a H$ genes) convert IAM into the auxin indole-3acetic acid (IAA) (Schröder et al. 1984; Thomashow et al. 1984, 1986). Whereas iaaM and iaaH genes always occur together, the iaaM homolog orf8 lacks an accompanying $i a a H$ gene, suggesting that it may have a different role. Indeed, orf 8 induces only low (Lemcke et al. 2000; Lemcke and Schmülling 1998b) or undetectable (Otten and Helfer 2001) levels of IAM. Because of their intimate connection with IaaM proteins, the RolB-like sequences may be involved in IAA metabolism, transport, or perception.

Previously (Otten and Helfer 2001), we investigated the biological activity of the rolB-like extensions of A-iaaM (from $A$. tumefaciens strain Ach5) and A4-orf8 (from A. rhizogenes strain A4). Both were expressed in tobacco under control of the strong $2 \times 35 \mathrm{~S}$ promoter. Whereas the rolB-like sequence of A-iaaM did not cause any morphological changes, the rolB-like part of A4orf8 (A4-Norf8) induced stunted growth, intercostal chlorosis, and necrosis. A4-Norf8 plants contained high levels of glucose, fructose, sucrose, and starch. Such high levels could be due to a number of different mechanisms: increased synthesis, decreased metabolism, or modifications in export or import into certain parts of the plant or within particular cell compartments. Here, we report a detailed analysis of two independent A4-Norf8 lines and show that the rolB-like sequence of A4-orf8 inhibits sucrose export from source leaves.

\section{RESULTS}

Growth of 2x35S-A4-Norf8 tobacco plants.

In a preliminary analysis of primary tobacco regenerants carrying the $5^{\prime}$ rolB-like part of A4-orf8 from A. rhizogenes strain A4 and a GUS marker (2x35S-A4-Norf8 plants) (Otten and Helfer 2001), we showed that such plants accumulated high levels of hexoses and starch. Further studies on the underlying mechanisms required the use of genetically well-characterized lines. GUS tests of F1 seedlings from a series of selfed primary $2 \times 35 \mathrm{~S}-\mathrm{A} 4-$ Norf 8 regenerants (results not shown) allowed us to identify two independent heterozygous singlecopy lines, called 2.32 (weak phenotype) and 2.5 (strong phenotype). These lines were selfed, yielding four different genotypes (heterozygous $2.5-1 \mathrm{x}$ and $2.32-1 \mathrm{x}$ and homozygous $2.5-$ $2 \mathrm{x}$ and 2.32-2x plants) showing different growth rates (Fig. 1A through E). Leaves of 2.5-1x, 2.32-1x, and 2.32-2x plants developed to normal sizes, whereas those of 2.5-2x seedlings remained very small. Stem growth decreased in the order $2.32-1 \mathrm{x}$, $2.5-1 \mathrm{x}, 2.32-2 \mathrm{x}$, and 2.5-2x (Fig. 2A); 2.5-2x stems did not elongate at all (Fig. 2B). At later stages, leaves of 2.5-1x, 2.5-2x, and 2.32-2x plants developed intercostal chlorosis starting 
from the apical side of the leaf. Although 2.32-1x and 2.5-1x plants flowered, 2.32-2x and 2.5-2x plants did not (not shown). Growth inhibition of 2.32-1x, 2.5-1x, and 2.32-2x plants was correlated with $2 \times 35 \mathrm{~S}-\mathrm{A} 4-$ Norf8 expression levels as shown by Northern analysis (Fig. 2C). The 2.5-2x plants were too abnormal to be analyzed for RNA levels. Accumulation of hexoses and starch in 2.5-1x and 2.5-2x plants was analyzed in more detail.

\section{Accumulation of hexoses and starch}

in developing $2 \times 35 \mathrm{~S}-\mathrm{A} 4-N o r f 8$ tobacco plants.

At the four-leaf stage, 2.5-2x plants contained already high levels of glucose, fructose, sucrose, and starch with a strong gradient from young to old leaves. In 2.5-1x plants, levels at this stage were slightly higher compared with normal plants (Fig. 3A). Within mature 2.5-1x 19-leaf plants (Fig. 3B), levels of hexoses and starch varied according to leaf size: they were slightly less than normal in small leaves (length of less than $5 \mathrm{~cm}$, leaf numbers 16 through 19) but higher than normal at later growth stages. Within a single leaf, a gradient devel-
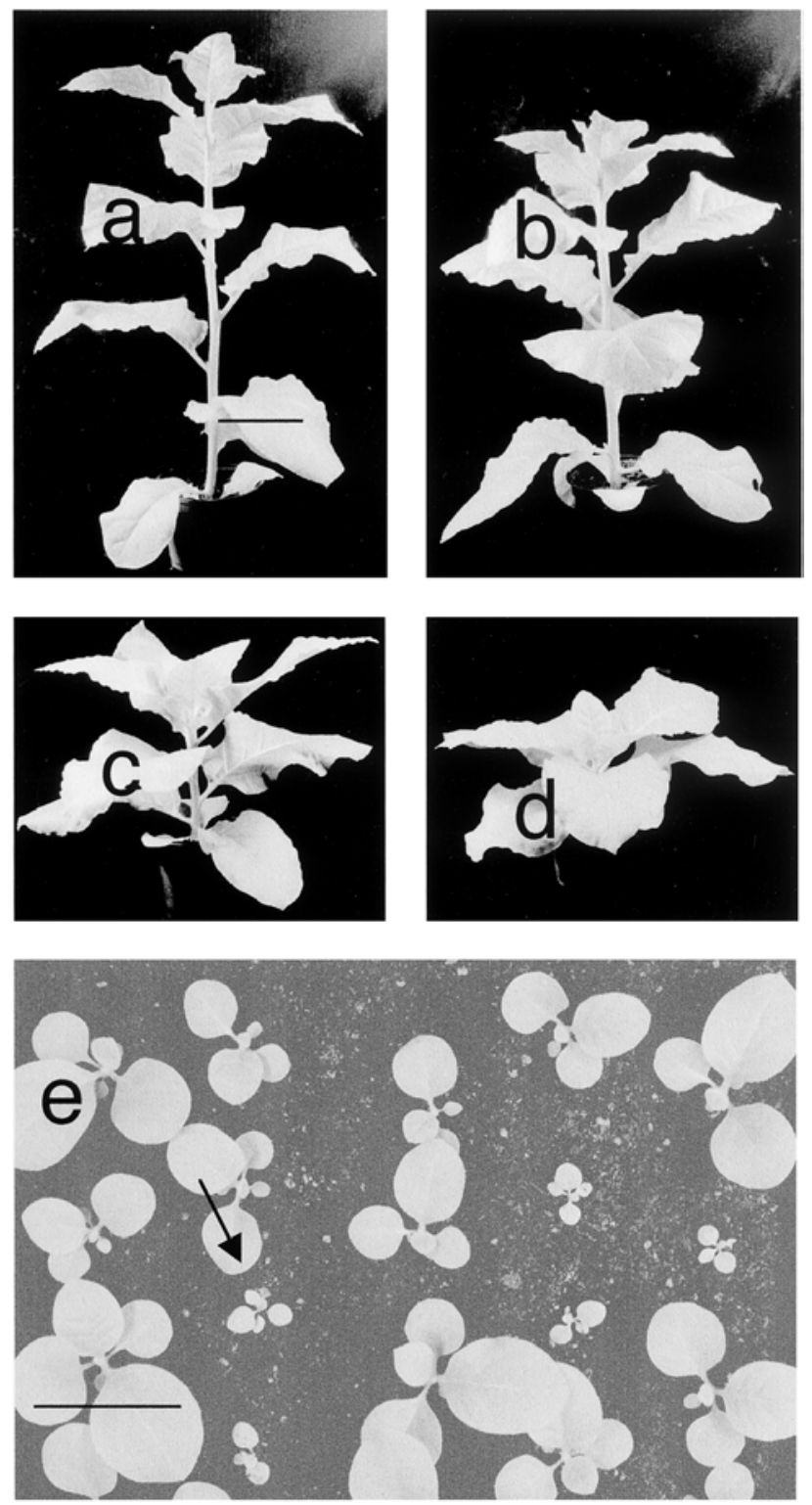

Fig. 1. Phenotype of different $2 \times 35 S-A 4-N o r f 8$ lines. A, Wild type, B, 2.32-1x, C, 2.5-1x, and D, 2.32-2x 55 days after sowing. Scale bar $=10$ cm. E, 2.5-1x F1 population 30 days after sowing. Scale bar $=5 \mathrm{~cm}$. Arrow indicates a 2.5-2x plant. oped, with highest concentrations for all compounds at the apical end (Fig. 3C). We also investigated sink tissues. Petioles of 2.5-1x plants contained lower levels of glucose, fructose, sucrose, and starch than normal (Fig. 3D). The same pattern was found for midribs (not shown). Another sink tissue, roots, showed reduced growth compared with normal plants (Fig. 4).

\section{Anatomical analysis of $2.5-1 x$ plants.}

Anatomical sections from wild-type and 2.5-1x leaves showed that, in 2.5-1x leaves, starch accumulated in epidermal cells, palisade, and spongy mesophyll cells and in the bundle
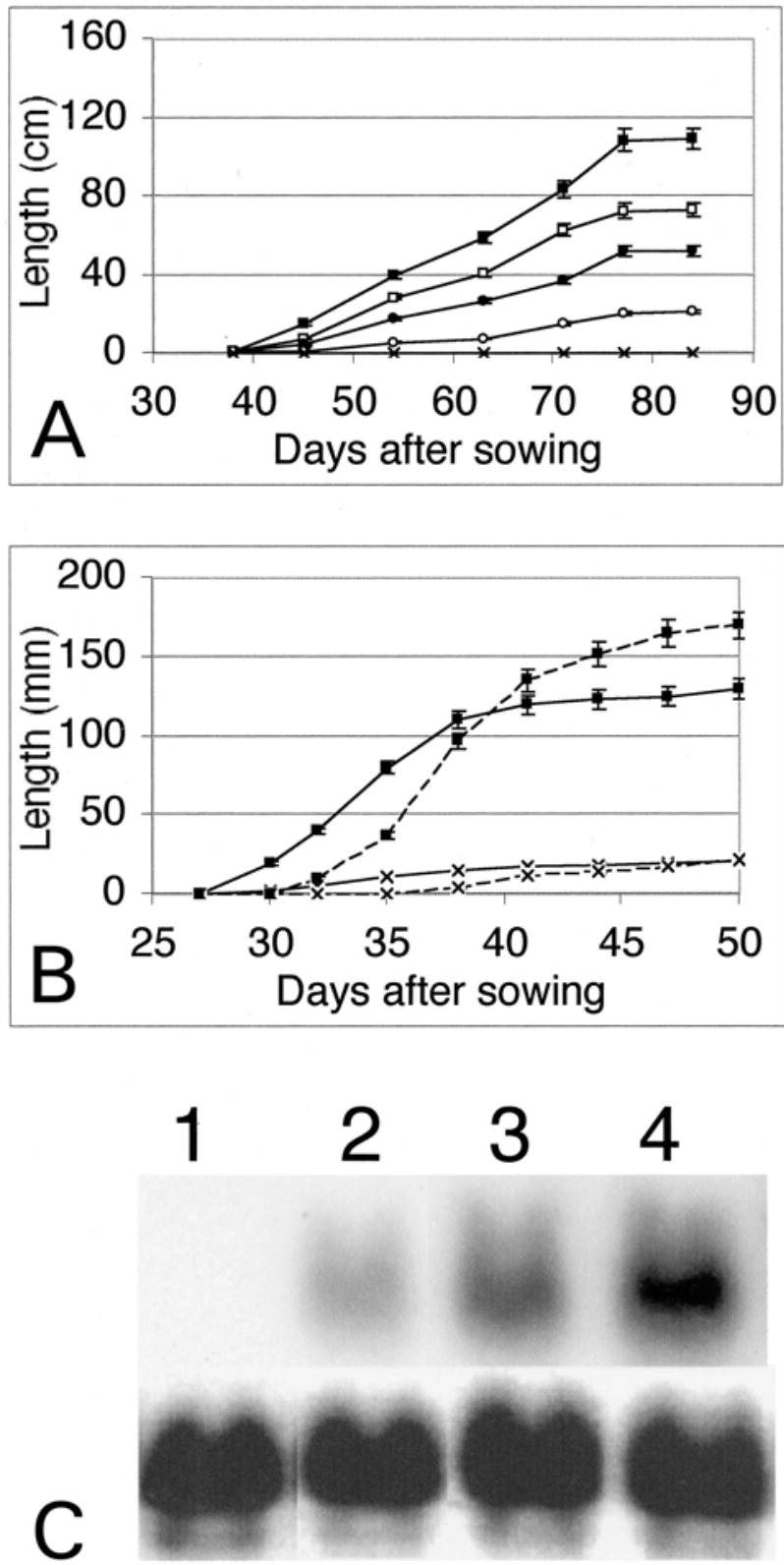

Fig. 2. Growth of different 2x35S-A4-Norf8 lines and transgene expression. Length was measured and averaged for 10 plants per line. Vertical bars indicate standard errors. A, Stem growth. Closed squares = wild type, open squares $=2.32-1 \mathrm{x}$, closed circles $=2.5-1 \mathrm{x}$, open circles $=2.32-2 \mathrm{x}$, and crosses $=2.5-2 \mathrm{x} . \mathbf{B}$, Leaf growth. Closed squares, continuous line $=$ wild type, third leaf; closed squares, dashed line = wild type, fourth leaf; crosses, continuous line $=2.5-2 \mathrm{x}$, third leaf; and crosses, dashed line $=$ 2.5-2x, fourth leaf. (Growth of 2.32-1x, 2.5-1x, and 2.32-2x leaves was similar to that of wild-type leaves). C, Northern analysis of wild-type, 2.32-1x, 2.5-1x, and 2.32-2x plants. Top: bands hybridizing to orf8. Bottom: ethidium-stained 28S RNA as internal reference. 
sheath cells, but not in companion cells, vascular parenchyma, or sieve elements (Fig. 5). This suggests that sucrose transport is blocked before entry in the vascular system.

\section{Reduction of sucrose export as measured by petiole exudation.}

The data presented above indicate a decrease in sucrose export from source to sink tissues in $2 \times 35 \mathrm{~S}-\mathrm{A} 4-$ Norf8 plants. This was further tested by infiltration of leaves with ${ }^{14} \mathrm{C}$-sucrose and monitoring export of label by petiole exudation in the dark over a period of $14 \mathrm{~h}$. The $2.5-1 \mathrm{x}$ plants exported radioactive label at a rate of only $15 \%$ of that of wild-type plants (Fig. 6A). In a second approach, source leaves were labeled with ${ }^{14} \mathrm{CO}_{2}$ and, after a chase period in the light, export of label was measured by petiole exudation in the dark over a period of $19 \mathrm{~h}$.

Leaves from control and transgenic plants incorporated between 2 and $5 \mathrm{mmol}$ of $\mathrm{CO}_{2} \mathrm{~m}^{-2} \mathrm{~h}^{-1}$. No significant difference between control plants and transgenic plants in the incorporation of labeled $\mathrm{CO}_{2}$ was observed during the pulse. During the 4-h light chase, only a small amount of the recently assimilated $\mathrm{CO}_{2}$ was exported via the vasculature to the petiole in transgenic and control plants. During the following dark chase, however, control leaves exported approximately $6.7 \%$ of the total assimilated label, whereas the transgenic line $2.32-1 \mathrm{x}$ exported only $0.88 \%$ of the recently assimilated $\mathrm{CO}_{2}$. The exudation of label from the transgenic lines 2.5-1x and 2.32-2x during the dark chase was barely detectable and exhibited a more than 300-fold reduction compared with the wild type (Fig. $6 \mathrm{~B})$. Autoradiography of the labeled leaf from the transgenic line 2.5-1x after the dark chase revealed that the remaining label was not evenly distributed across the leaf blade but was concentrated along the vasculature. In the control line, how- ever, the remaining label was almost evenly distributed over the whole leaf blade (Fig. 6C).

\section{Restoration of growth of $\mathbf{2 . 5 - 2 x}$ plants by grafting.}

The 2.5-2x seedlings stopped growing and became chlorotic when the leaves reached a length of approximately $3 \mathrm{~cm}$. When grafted onto normal tobacco plants with three source leaves, these plantlets resumed growth, forming many leaves, which subsequently accumulated high levels of starch and stopped growth. The leaf surface of the grafted plants increased 100-fold compared with nongrafted plants. No flowers were formed (not shown). Grafting of the less stunted 2.32-2x plants onto wildtype tobacco also restored growth and, unlike the $2.5-2 \mathrm{x}$ plants, allowed flowering and seed production (not shown).

\section{Growth of 2x35S-A4-Norf8 seedlings on medium with naphthalene acetic acid (NAA).}

Lemcke and Schmülling (1998b) reported that seed of tobacco plants expressing the intact A4-orf8 gene developed normally on $5 \mu \mathrm{M}$ NAA, unlike wild-type seed, which formed callus, suggesting an decrease in auxin sensitivity. The rolB gene increases auxin sensitivity (Nilsson and Olsson 1997); therefore, it was of interest to determine the effect of the rolB-like part of the A4-orf8 gene on auxin sensitivity. F1 seed from the 2.5-1x line were germinated on Murashige-Skoog (MS) medium with $0,0.5,1,5,10$, and $20 \mu \mathrm{M}$ NAA. Shoot inhibition became evident at $5 \mu \mathrm{M}$ and was essentially complete at 10 and $20 \mu \mathrm{M}$. At $5 \mu \mathrm{M}$ NAA, 111 seeds formed a callus with a shoot and 112 developed calli without shoots. GUS tests showed that 54 calli with shoots and 103 shootless calli were transformed. These values differ significantly from those expected in cases where A4Norf 8 has no effect on auxin sensitivity ( 83 and 84 ; $\mathrm{P}$ values of
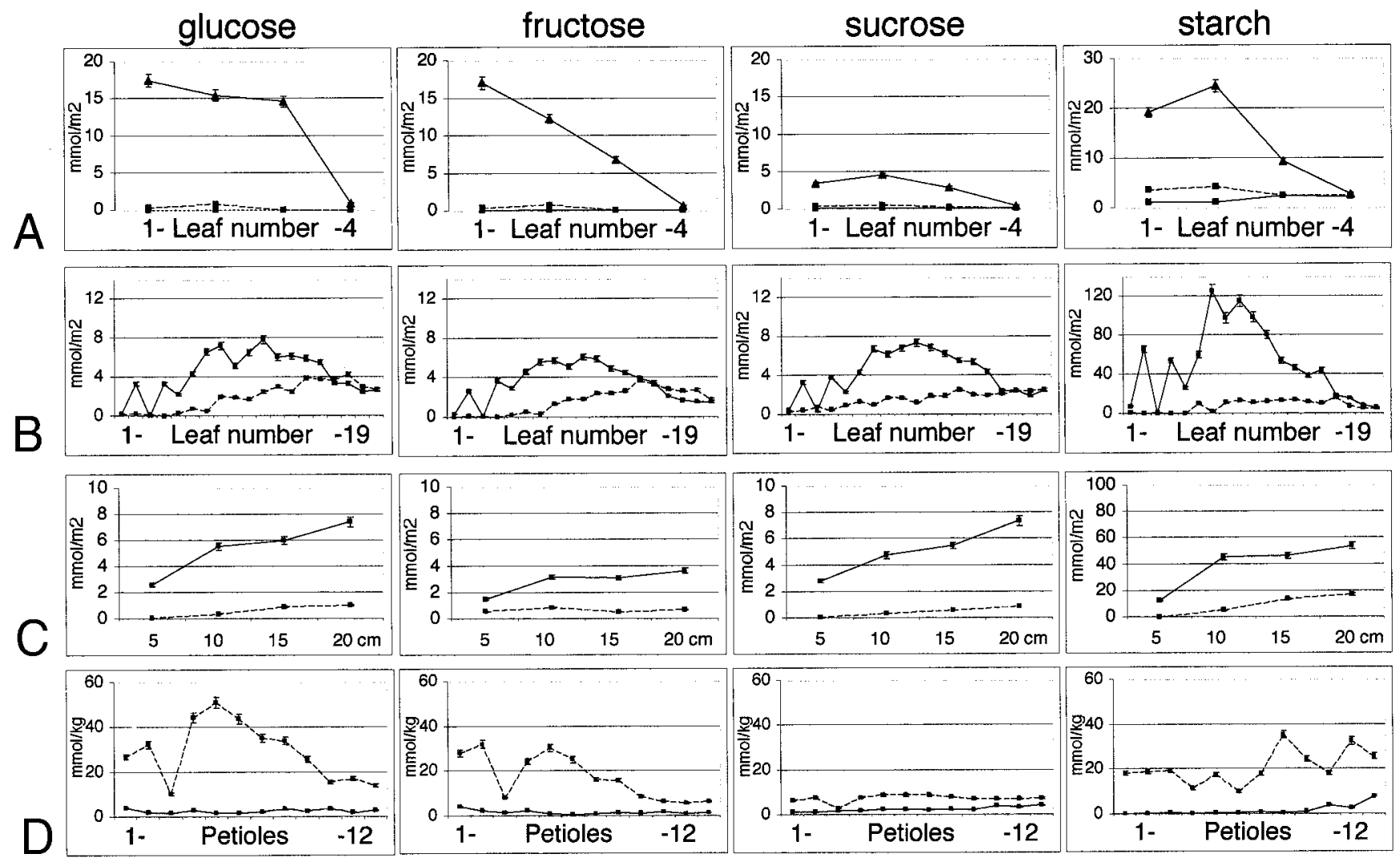

Fig. 3. Hexose and starch analysis of 2x35S-A4-Norf8 plants. A, Young four-leaf plants. True leaves (excluding cotyledons) are numbered in order of appearance. B, Mature 19-leaf plants. C, Gradients of hexoses and starch in the second full-grown leaf of 12-leaf plants (start of the scale at the base of the leaf). D, Hexoses and starch in petioles of 12-leaf plants. Symbols: squares, continuous line $=$ wild type; squares, dashed line $=2.5-1 \mathrm{x}$; and triangles $=2.5$ 2x. Vertical bars indicate standard errors. 
0.1 and 5\%, respectively). Thus, the A4-Norf8 gene increases the sensitivity of tobacco seedlings to NAA.

\section{DISCUSSION}

The 5' rolB-like part of the A. rhizogenes T-DNA gene orf8 induces a "high starch" phenotype in transgenic tobacco (Otten and Helfer 2001). Different mechanisms could lead to such a phenotype. The evidence presented here suggests that the accumulation of starch is caused by the inhibition of sucrose export from source leaves (Oparka and Turgeon 1999). The resulting deficiency of sucrose in sink tissues reduces stem size and, in more severe cases, leaf growth. Transgene expression levels correlate with levels of growth reduction.

The morphological and physiological properties of the $2 \times 35$ S-A4-Norf8 plants are similar to those of plants with antisense constructs derived from the $\mathrm{H}^{+}$-sucrose transporter encoding gene SUT1. Such plants are impaired in the loading of sucrose into the phloem of source leaves (Bürkle et al. 1998; Kühn et al. 1996; Riesmeier et al. 1994). During maturation, leaves of NtSUT1 antisense tobacco plants become first chlorotic in a basipetal way and necrotic at later stages, whereas sink leaves remain normal. In severely affected plants, leaf and root development are reduced and plants remain stunted without flowering. Concentrations of soluble sugars and starch increase and excess starch is not mobilized during the night (Bürkle et al. 1998). Inhibition of carbon export from leaves through the expression of a yeast-derived invertase in tobacco (Sonnewald et al. 1991; von Schaewen et al. 1990) and phloem-specific expression of an Escherichia coliderived pyrophosphatase (Lerchl et al. 1995) also lead to accumulation of soluble sugars and starch. In 2x35S-A4-Norf8 plants, hexoses and starch levels increase with a clear developmental pattern. In mature $2.5-1 x$ plants, levels in young leaves are slightly below normal but increase progressively in older leaves, after which intercostal chlorosis develops in a basipetal pattern. Sink tissues like midribs and petioles contain significantly less soluble sugars and starch compared with wild-type plants. Root growth is reduced.

These data suggest that A4-Norf8 overexpression leads to a block in the export of sucrose from source to sink tissues. Experimental data support these conclusions. Sucrose export measured by monitoring export of label from ${ }^{14} \mathrm{C}$-sucrose-fed leaves is reduced by $85 \%$ in $2.5-1 \mathrm{x}$ leaves. Pulse labeling of assimilates followed by dark chase clearly demonstrated that the transgenic 2x35S-A4-Norf8 plants display a dramatic reduction in the export of recently generated assimilates. This could be either due to (i) a restriction of symplastic transport between mesophyll cells, (ii) a block of export of sucrose from the mesophyll cells to the apoplast, (iii) a restriction in loading of sucrose into companion cells, or (iv) a hampered translocation of sucrose into sieve elements. Infiltration of sucrose into leaves mainly leads to
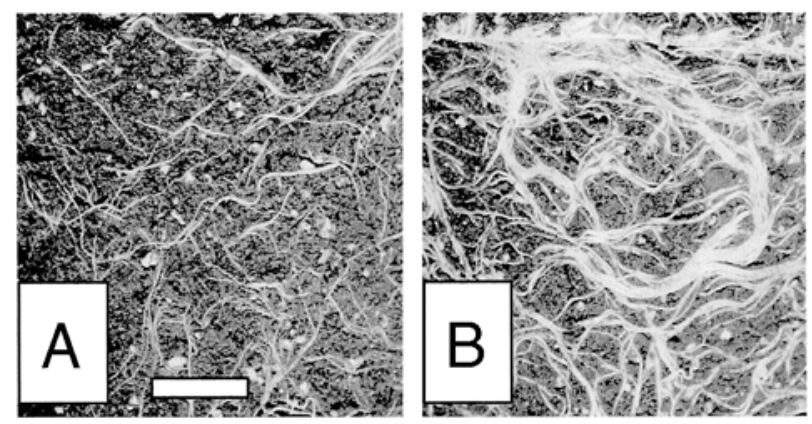

Fig. 4. Root growth of $\mathbf{A}, 2.5-1 \mathrm{x}$ and $\mathbf{B}$, wild-type plants. Scale bar $=3 \mathrm{~cm}$. accumulation of sucrose in the apoplastic space, and we observed that source leaves of the $2 \times 35 \mathrm{~S}-\mathrm{A} 4-$ Norf 8 plants did not efficiently translocate infiltrated sucrose to the sink tissues; therefore, we assume that either the uptake of sucrose from the apoplastic space into companion cells is limiting in the transgenic lines or the symplastic translocation of sucrose from companion cells to the sieve elements via branched type plasmodesmata is restricted. In addition, our observation that assimilates accumulate in the regions surrounding the vasculature in transgenic line 2.5-1x strongly suggests that overexpression of A4Norf8 leads to restriction in either assimilate uptake into the phloem or phloem translocation itself. In the light of the presented data, an effect of A4-Norf8 overexpression on symplastic transport between mesophyll cells or on the unloading of assimilates to the apoplast from mesophyll cells seems unlikely. Growth of 2.5-2x and 2.32-2x plants can be restored by grafting, suggesting that the unloading of sucrose by sink tissues is not impaired.

Further studies should aim at an understanding of the mechanism by which A4-Norf8 inhibits sucrose transport. Protein localization studies and tissue-specific expression experiments may help to solve this question. Subsequently, such studies could be extended to plants that express the closest homologs of A4-Norf8: $r o l B$ and $\mathrm{rolB}^{T R}$.

It will also be of interest to determine the function of the $\mathrm{C}$ terminal part of the A4-Orf8 protein (A4-COrf8) and the way A4-COrf8 and A4-NOrf8 interact. In spite of the fact that A4COrf8 shows considerable homology to C-IaaMs and the IaaM
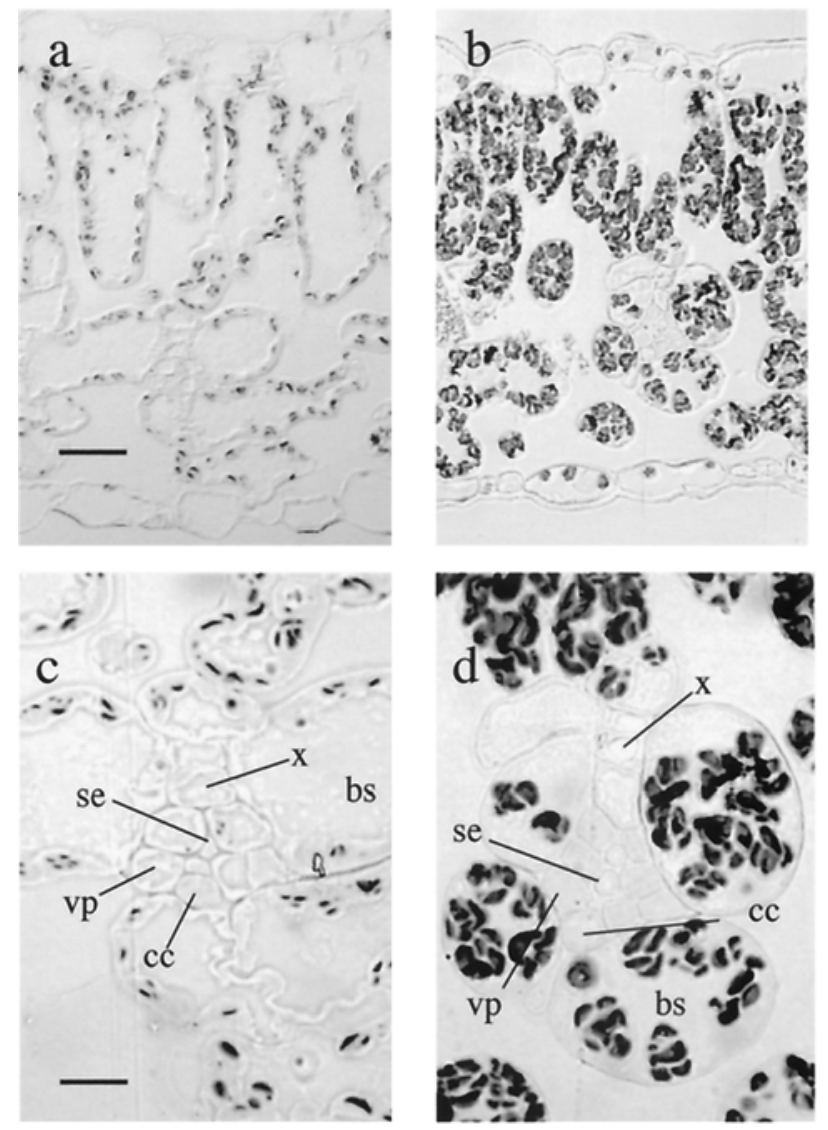

Fig. 5. Transverse sections of leaves from a mature 19-leaf wild-type and 2.5-1x tobacco plants, stained for starch with iodine and viewed with phase contrast optics. A, Wild-type, overview, magnification $\times 13,500 ; \mathbf{B}$, $2.5-1 \mathrm{x}$, overview, magnification $\times 13,500$; $\mathbf{C}$, wild-type, magnification $\times 65,000 ; \mathbf{D}, 2.5-1 x$, magnification $\times 65,000$. Scale bars: A and $B=25 \mu \mathrm{m}$, $\mathrm{C}$ and $\mathrm{D}=10 \mu \mathrm{m}$. Symbols: $\mathrm{se}=$ sieve element, $\mathrm{bs}=$ bundle sheath cell, $\mathrm{x}$ $=$ xylem, $\mathrm{cc}=$ companion cell, and $\mathrm{vp}=$ vascular parenchyma. 
proteins from Pseudomonas and Erwinia spp., it does not seem to encode high levels of IAM synthesis (Lemcke et al. 2000; Lemcke and Schmülling 1998b), if at all (Otten and Helfer 2001). The situation is further complicated by the fact that tobacco plants carrying the A4-orf8 gene under control of a tetracycline-dependent $35 \mathrm{~S}$ promoter were morphologically normal (Lemcke and Schmülling 1998b), which is rather unexpected in view of the "high starch" phenotype encoded by the
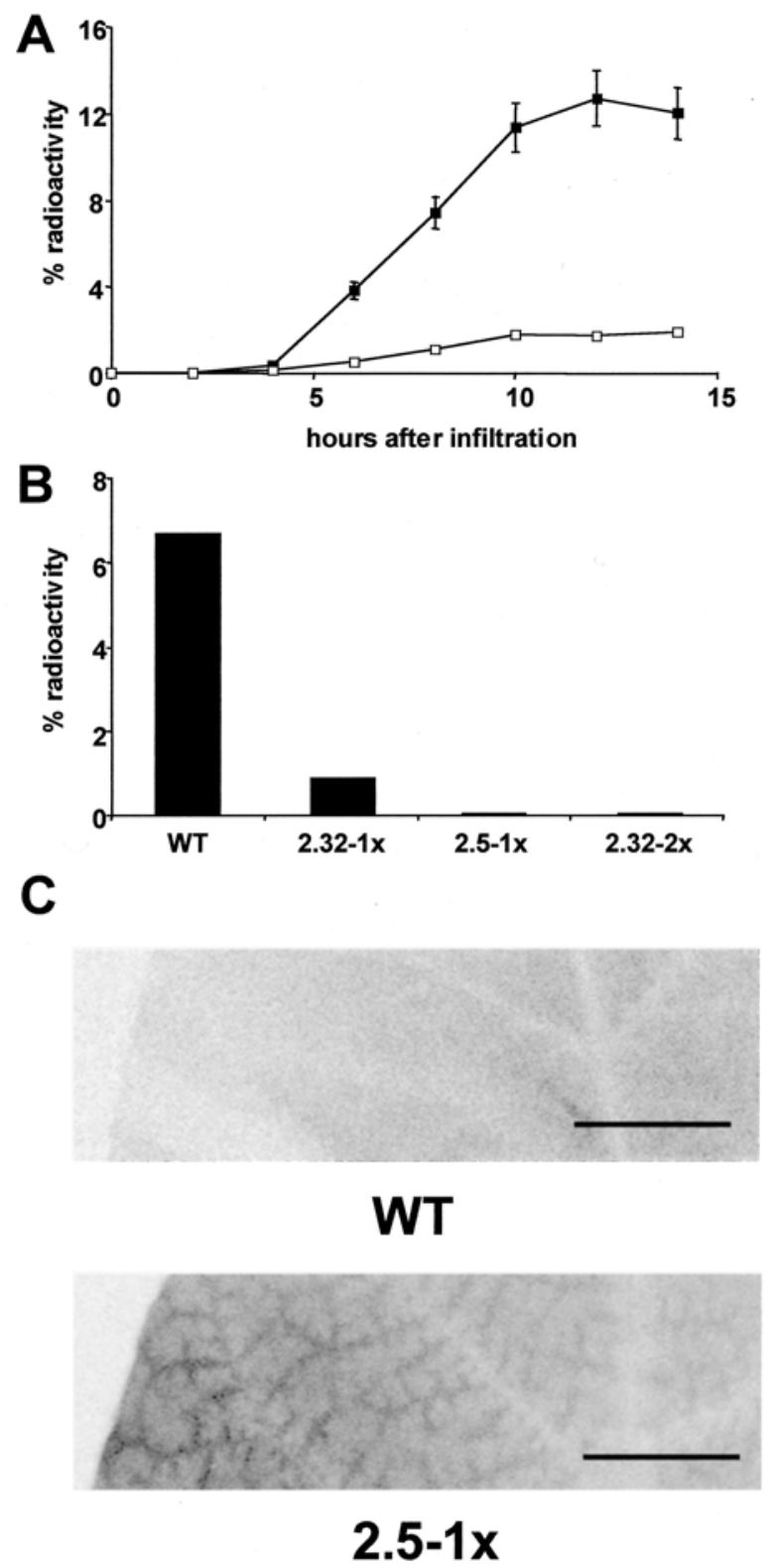

Fig. 6. Export of label from ${ }^{14} \mathrm{C}$-sucrose-infiltrated leaves and from leaves labeled with ${ }^{14} \mathrm{CO}_{2}$. A, Exudation of ${ }^{14} \mathrm{C}$ label from ${ }^{14} \mathrm{C}$-sucrose-infiltrated leaves. Export was calculated as a percentage of infiltrated label. Closed squares $=$ wild-type, open squares $=2.5-1 \mathrm{x}$ plants. The $2 \times 35 \mathrm{~S}-\mathrm{A} 4-$ Norf 8 plants show a strong decrease in export of label. B, Exudation of ${ }^{14} \mathrm{C}$ label from leaves after $40 \mathrm{~min}$ of labeling, a 4-h chase period in the light, and a 19-h chase period in the dark. Export was calculated as a percentage of total incorporation during the pulse. The three $2 \times 35 \mathrm{~S}-\mathrm{A} 4-$ Norf 8 plants show a strong decrease in export of label. C, Autoradiographs of wildtype and 2.5-1x leaves after the dark chase. Whereas wild-type leaves show a low and homogeneous labeling pattern, the 2.5-1x leaves show a more intense labeling concentrated around the minor veins. Scale bars $=2$ $\mathrm{cm}$.
5' part of this gene. Possibly, the C-terminal part of Orf8 reverses or counteracts the activity of the RolB-like part. Comparative studies with $2 \times 35 \mathrm{~S}-\mathrm{A} 4-$ orf8 and $2 \times 35 \mathrm{~S}-\mathrm{A} 4-$ Corf8 plants may clarify this point. It also would be of interest to combine $2 \times 35 \mathrm{~S}-\mathrm{A} 4-$ Corf8 and $2 \times 35 \mathrm{~S}-\mathrm{A} 4-$ Norf8 constructs in one plant and compare the resulting phenotype with that of 2x35S-A4-orf8 plants.

Lemcke and Schmülling (1998b) reported that A4-orf8 overexpressing seedlings germinated at a normally inhibitory NAA concentration of $5 \mu \mathrm{M}$, and concluded that orf8 decreased auxin sensitivity. We found that $2 \times 35 \mathrm{~S}-\mathrm{A} 4-$ Norf8 plants germinated less well under these conditions. Thus, the decrease in auxin sensitivity of A4-orf8 seedlings does not appear to be due to the $5^{\prime}$ part of the gene. It is not clear how the supposed IAM synthesis activity of A4-orf8 could lead to decreased auxin sensitivity.

It remains to be established whether sucrose export inhibition and increased auxin sensitivity in 2x35S-A4-Norf8 plants are causally related. Auxin gradients are known to be essential for the development of the leaf vascular system (Berleth and Sachs 2001; Dengler and Kang 2001). Increased auxin sensitivity may lead to a modification of the vascular system and subsequent changes in sucrose transport. Our anatomical studies did not show gross alterations of the vascular system. However, it is conceivable that minor changes in anatomy could lead to cumulative effects on sucrose transport. The RolB-like extension of the Orf8 protein is not only an interesting model to study other RolB-like proteins, but also can be used as a new tool to study sucrose transport.

\section{MATERIALS AND METHODS}

Hexoses and starch measurements.

Hexoses and starch were measured as described using enzymatic assays yielding NADH (Otten and Helfer 2001). All experiments were done with plant batches that had been grown in a greenhouse under controlled temperature $\left(22\right.$ to $24^{\circ} \mathrm{C}$ during the day, 18 to $19^{\circ} \mathrm{C}$ during the night, $16 \mathrm{~h}$ of light, and $8 \mathrm{~h}$ of dark) and humidity (60 to $80 \%$ ) conditions and watered daily with a standard nutrient solution. Samples were always taken 4 to $5 \mathrm{~h}$ after sunrise. The standard error of the data was less than 5\%. All experiments were repeated at least twice with different plant batches and yielded essentially the same results.

\section{Northern analysis.}

Total RNA was extracted according to Verwoerd and associates (1989) and run on a $1 \%$ agarose gel. RNA (15 mg) was loaded per lane and, after transfer to nitrocellulose, hybridized with the ${ }^{32} \mathrm{P}$-labeled orf 8 coding sequence. Amounts were standardized using ethidium bromide staining of ribosomal $28 \mathrm{~S}$ RNA. Extraction of sufficiently pure RNA from 2.5-2x plants proved to be difficult due to the very high starch levels in these plants.

\section{Petiole exudation after infiltration with ${ }^{\mathbf{1 4}} \mathrm{C}$-sucrose.}

Petiole exudation experiments were carried out according to King and Zeevaart (1974). The youngest fully grown leaves (length $20 \mathrm{~cm}$ ) of mature plants with 20 leaves were infiltrated with $0.1 \mathrm{ml}$ of a $1-\mathrm{mM}{ }^{14} \mathrm{C}(\mathrm{U})$-sucrose solution (3.7 MBq). After $30 \mathrm{~min}$, individual leaves were detached and placed in 10$\mathrm{ml}$ plastic tubes filled with $4.5 \mathrm{ml}$ of a $20-\mathrm{mM}$ EDTA solution. The tubes were placed in racks in the dark in large plastic boxes saturated with water vapor to avoid evaporation from the leaves. Duplicate samples of $0.1 \mathrm{ml}$ were taken at 2-h intervals and counted with a Beckman LS6500 scintillation counter (Fullerton, CA, U.S.A.). Experiments were repeated three times. Standard error of the data was less than $5 \%$. 


\section{Petiole exudation after ${ }^{14} \mathrm{CO}_{2}$ labeling.}

Before the ${ }^{14} \mathrm{CO}_{2}$ feeding, plants were subjected to prolonged darkness of $20 \mathrm{~h}$ and light-adapted for $15 \mathrm{~min}$ before single leaves of comparative whorl positions were harvested and fixed in a chamber. Detached leaves were preilluminated for $5 \mathrm{~min}$ at $200 \mu \mathrm{mol} \mathrm{m} \mathrm{m}^{-2} \mathrm{~s}^{-1}$ before a 40 -min pulse with 80 $\mu \mathrm{Ci}{ }^{14} \mathrm{CO}_{2}\left(0.4 \mathrm{~Bq}\right.$. per nmol of $\mathrm{HCO}_{3}{ }^{-}$) was applied. At the end of the pulse, leaf disks of $2.5 \mathrm{~cm}^{2}$ were extracted in $80 \%$ ethanol and processed as described by Häusler and associates (1998) to determine the incorporation of ${ }^{14} \mathrm{C}$ into the $\mathrm{EtOH}-$ soluble and insoluble fraction. To collect the exudates, the petioles of the leaves were transferred to microcentrifuge tubes containing $10 \mathrm{mM}$ HEPES, $\mathrm{pH} 7.5$, and $0.5 \mathrm{mM}$ EDTA (Hansen and Cohen 1985). The leaves were placed into transparent incubation chambers saturated with humidity and the buffer was exchanged after $4 \mathrm{~h}$ at $100 \mu \mathrm{mol} \mathrm{m} \mathrm{m}^{-2} \mathrm{~s}^{-1}$. The chambers were darkened and the exudates were collected after $19 \mathrm{~h}$ in the dark. The ${ }^{14} \mathrm{C}$ in the samples was quantified by scintillation counting. The export of labeled compounds during the light and the dark chases was calculated as percentage of total incorporation during the pulse.

\section{Autoradiography of labeled leaves.}

At the end of the dark chase, the leaves were incubated on phosphostorage screens at $4^{\circ} \mathrm{C}$ for $14 \mathrm{~h}$. The image was recorded with a phospho-imager (Storm 860; Molecular Dynamics, Sunnyvale, CA, U.S.A.).

\section{Anatomical studies.}

Leaves from wild-type tobacco plants and 2.5-1x plants were fixed in $5 \%$ glutaraldehyde, $0.1 \mathrm{M}$ phosphate, $\mathrm{pH} 7.2$ for $7 \mathrm{~h}$ at $4^{\circ} \mathrm{C}$, washed overnight at $4^{\circ} \mathrm{C}$ with phosphate buffer, fixed for $2 \mathrm{~h}$ at $4^{\circ} \mathrm{C}$ with $1 \%$ osmium tetroxide, washed in water, dehydrated in a graded ethanol series, and embedded in LR White embedding medium. Sections of $0.35 \mu \mathrm{m}$ were cut with a diamond knife on a Reichert-Jung Ultracut microtome (Vienna, Austria), mounted on glass slides, and stained for starch with iodine. Sections were viewed and photographed on a Nikon Eclipse E800 microscope (Nikon France, Paris) equipped with a Sony DXC950 camera (Tokyo) and image analysis software (VisioLab2000; Biocom, Paris).

\section{Germination of seedlings in vitro.}

F1 seedlings from a 2.5-1x plant were sterilized and placed on MS medium (Murashige and Skoog 1962) with different NAA concentrations. Results were scored 7 weeks later.

\section{Root growth analysis.}

Plants were grown in large pots $(15 \mathrm{~cm}$ in diameter) up to the 20-leaf stage. Stems and leaves were cut off and the soil clump was carefully removed and photographed.

\section{ACKNOWLEDGMENTS}

We thank M. Stitt, P. Geigenberger, H.-D. Behnke, and D. Vreugdenhil for useful discussions and R. Wagner, S. Staerck, and M. Kernéis for providing greenhouse plants. M. Umber was supported by a DEA grant from the French Ministry for Research and Technology.

\section{LITERATURE CITED}

Berleth, T., and Sachs, T. 2001. Plant morphogenesis: Long-distance coordination and local patterning. Curr. Opin. Plant Biol. 4:57-62.

Bürkle, L., Hibberd, J. M., Quick, W. P., Kühn, C., Hirner, B., and Frommer, W. B. 1998. The $\mathrm{H}^{+}$-sucrose cotransporter NtSUT1 is essential for sugar export from tobacco leaves. Plant Physiol. 118:59-68.

Comai, L., and Kosuge, T. 1982. Cloning and characterization of iaaM, a virulence determinant of Pseudomonas savastanoi. J. Bacteriol. 149:40-46.

Dengler, N., and Kang, J. 2001. Vascular patterning and leaf shape. Curr.
Opin. Plant Biol. 4:50-56.

Gafni, Y., Manulis, S., Kunik, T., Lichter, A., Barash, I., and Ophir, Y. 1997. Characterization of the auxin synthesis genes of Erwinia herbicola pv. gypsophilae. Isr. J. Plant Sci. 45:279-284.

Gaudin, V., Vrain, T., and Jouanin, L. 1994. Bacterial genes modifying hormonal balances in plants. Plant Physiol. Biochem. 32:11-29.

Hansen, G., Vaubert, D., Héron, J. N., Clérot, D., Tempé, J., and Brevet, J. 1993. Phenotypic effects of overexpression of Agrobacterium rhizogenes T-DNA ORF13 in transgenic tobacco plants are mediated by diffusible factors. Plant J. 4:581-585.

Hanson, S. D., and Cohen, J. D. 1985. A technique for collection of exudate from pea seedlings. Plant Physiol. 78:734-738.

Häusler, R. E., Schlieben, H. N., Schulz, B., and Flügge, U-I. 1998. Compensation of decreased triose phosphate/phosphate translocator activity by accelerated starch turnover and glucose transport in transgenic tobacco. Planta 204:366-376.

Hooykaas, P. J. J., Den Dulk-Ras, H., and Schilperoort, R. A. 1988. The Agrobacterium tumefaciens T-DNA gene $6 b$ is an onc gene. Plant Mol. Biol. 11:791-794.

King, R. W., and Zeevaart, J. A. D. 1974. Enhancement of phloem exudation from cut petioles by chelating agents. Plant Physiol. 53:96-103.

Körber, H., Strizhov, N., Staiger, D., Feldwisch, J., Olsson, O., Sandberg, G., Palme, K., Schell, J., and Koncz, C. 1991. T-DNA gene 5 of Agrobacterium modulates auxin response by autoregulated synthesis of a growth hormone antagonist in plants. EMBO (Eur. Mol. Biol. Organ.) J. 10:3983-3991.

Kühn, C., Quick, W. P., Schulz, A., Sonnewald, U., and Frommer, W. B. 1996. Companion cell-specific inhibition of the potato sucrose transporter SUT1. Plant Cell Environ. 19:1115-1123.

Lemcke, K., Prinsen, E., van Onckelen, H., and Schmülling, T. 2000. The ORF8 gene product of Agrobacterium rhizogenes TL-DNA has tryptophan 2-monooxygenase activity. Mol. Plant-Microbe Interact. 13:787 790.

Lemcke, K., and Schmülling, T. 1998a. A putative rolB gene homologue of the Agrobacterium rhizogenes TR-DNA has different morphogenetic activity in tobacco than rolB. Plant Mol. Biol. 36:803-808.

Lemcke, K., and Schmülling, T. 1998b. Gain of function assays identify non-rol genes from Agrobacterium rhizogenes TL-DNA that alter plant morphogenesis or hormone sensitivity. Plant J. 15:423-433.

Lerchl, J., Geigenberger, P., Stitt, M., and Sonnewald, U. 1995. Impaired photoassimilate partitioning caused by phloem-specific removal of pyrophosphate can be complemented by a phloem-specific cytosolic yeast-derived invertase in transgenic plants. Plant Cell 7:259-270.

Levesque, H., Delepelaire, P., Rouzé, P., Slightom, J., and Tepfer, D. 1988 Common evolutionary origin of the central portion of the Ri TL-DNA of Agrobacterium rhizogenes and the Ti T-DNAs of Agrobacterium tumefaciens. Plant Mol. Biol. 11:731-744.

Messens, E., Lenaerts, A., van Montagu, M., and Hedges, R. W. 1985. Genetic basis for opine secretion from crown gall tumor cells. Mol. Gen. Genet. 199:344-348.

Murashige, T., and Skoog, S. 1962. A revised medium for rapid growth and bioassays with tobacco tissue cultures. Physiol. Plant. 15:473-497.

Nilsson, O., and Olsson, O. 1997. Getting to the root: The role of the Agrobacterium rhizogenes rol genes in the formation of hairy roots. Physiol. Plant. 100:463-473.

Oparka, K. J., and Turgeon, R. 1999. Sieve elements and companion cellstraffic control centers of the phloem. Plant Cell 11:739-750.

Otten, L., and Helfer, A. 2001. Biological activity of the rolB-like $5^{\prime}$ end of the A4-orf8 gene from the Agrobacterium rhizogenes TL-DNA. Mol. Plant-Microbe Interact. 14:405-411.

Otten, L., Salomone, J-Y., Helfer, A., Schmidt, J., Hammann, P., and De Ruffray, P. 1999. Sequence and functional analysis of the left-hand part of the T-region from the nopaline-type Ti plasmid pTiC58. Plant Mol. Biol. 41:765-776.

Otten, L., and Schmidt, J. 1998. A T-DNA from the Agrobacterium limited-host range strain AB2/73 contains a single oncogene. Mol. PlantMicrobe Interact. 11:335-342.

Riesmeier, J. W., Willmitzer, L., and Frommer, W. B. 1994. Antisense repression of the sucrose transporter affects assimilate partitioning in transgenic potato plants. EMBO (Eur. Mol. Biol. Organ.) J. 13:1-7.

Schmülling, T., Schell, J., and Spena, A. 1988. Single genes from Agrobacterium rhizogenes influence plant development. EMBO (Eur. Mol Biol. Organ.) J. 7:2621-2629.

Schröder, G., Waffenschmidt, S., Weiler, E. W., and Schröder, J. 1984. The T-region of Ti plasmids codes for an enzyme synthesizing indole-3-acetic acid. Eur. J. Biochem. 138:387-391.

Sonnewald, U., Brauer, M., von Schaewen, A., Stitt, M., and Willmitzer, L. 1991. Transgenic tobacco plants expressing yeast-derived invertase in either the cytosol, vacuole or apoplast: A powerful tool for studying sucrose metabolism and sink/source interactions. Plant J. 1:95-106. 
Thomashow, L. S., Reeves, S., and Thomashow, M. F. 1984. Crown gall oncogenesis: Evidence that a T-DNA gene from the Agrobacterium Ti plasmid pTiA6 encodes an enzyme that catalyzes synthesis of indoleacetic acid. Proc. Natl. Acad. Sci. U.S.A. 81:5071-5075

Thomashow, M. F., Hugly, S., Buchholz, W. G., and Thomashow, L. S. 1986. Molecular basis for the auxin-independent phenotype of crown gall tissues. Science 231:616-618.

Tinland, B., Fournier, P., Heckel, T., and Otten, L. 1992. Expression of a chimeric heat-shock-inducible Agrobacterium $6 b$ oncogene in Nicotiana rustica. Plant Mol. Biol. 18:921-930.

Tinland, B., Huss, B., Paulus, F., Bonnard, G., and Otten, L. 1989. Agrobacterium tumefaciens $6 b$ genes are strain-specific and affect the activity of auxin as well as cytokinin genes. Mol. Gen. Genet. 219:217-224.

Van Onckelen, H., Prinsen, E., Inzé, D., Rüdelsheim, P., Van Lijsebettens, M., Follin, A., Schell, J., Van Montagu, M., and De Greef, J. 1986. Agrobacterium T-DNA gene 1 codes for tryptophan 2-monooxygenase activity in tobacco crown gall cells. FEBS Lett. 198:357-360.
Van Onckelen, H., Rüdelsheim, P., Inzé, D., Follin, A., Messens, E., Horemans, S., Schell, J., Van Montagu, M., and De Greef, J. 1985. Tobacco plants transformed with the Agrobacterium T-DNA gene 1 contain high amounts of indole-3-acetamide. FEBS (Fed. Eur. Biochem. Soc.) Lett. 181:373-376.

Verwoerd, T. C., Dekker, B. M. M., and Hoekema, A. 1989. A small-scale procedure for the rapid isolation of plant RNAs. Nucleic Acids Res. $17: 2362$.

Von Schaewen, A., Stitt, M., Schmidt, R., Sonnewald, U., and Willmitzer, L. 1990. Expression of a yeast-derived invertase in the cell wall of tobacco and Arabidopsis plants leads to accumulation of carbohydrates and inhibition of photosynthesis and strongly influences growth and phenotype of transgenic tobacco plants. EMBO (Eur. Mol. Biol. Organ.) J. 9:3033-3044.

Wabiko, H., and Minemura, M. 1996. Exogenous phytohormone-independent growth and regeneration of tobacco plants transgenic for the $6 b$ gene of Agrobacterium AKE10. Plant Physiol. 112:939-951. 